\title{
Linn da Quebrada: o corpo trans na experiência urbana
}

DOI: http://dx.doi.org/10.21165/el.v48i3.2361

\section{Redson Pagnan ${ }^{1}$ \\ Marília Giselda Rodrigues ${ }^{2}$}

\section{Resumo}

Este artigo apresenta uma análise da canção "Mulher", da artista Linn da Quebrada, veiculada na obra audiovisual blasFêmea, a partir da perspectiva teórico-metodológica da Análise do Discurso de linha francesa. O tema que atravessa a produção é a questão do "ser" mulher a partir da vivência do corpo transexual e periférico, em relação ao espaço urbano, portanto, social, habitado por essa persona. Diante desse emblema contemporâneo, trazemos para o debate a relação entre gênero, sexualidade e espaço urbano, a partir da prática discursiva intersemiótica de Linn da Quebrada, a fim de repensar as formas de construção de identidades de gênero, partindo da desconstrução das cisheteronormatividades, essas dadas como naturais. Faremos a exposição do tema chave, gênero e espaço urbano, aqui, já que nos interessa discutir sobre o papel social que a arquitetura desempenha em nossa cultura, e logo depois faremos uma breve reflexão a respeito dos conceitos utilizados para, então, expormos nossa análise.

Palavras-chave: prática discursiva intersemiótica; ethos discursivo; queer; espaço urbano.

\footnotetext{
1 Universidade Presbiteriana Mackenzie (UPM), São Paulo, São Paulo, Brasil; redson.pagnan@gmail.com; https://orcid.org/0000-0002-1912-6661

2 Universidade de Franca (Unifran), Franca, São Paulo, Brasil; marilia.rodrigues@unifran.edu.br; https://orcid.org/0000-0003-3135-3784
} 


\title{
Linn da Quebrada: the trans body in the urban experience
}

\begin{abstract}
This article presents the analysis of the song "Mulher" by the artist Linn da Quebrada, which is part of the audiovisual work blasFêmea, from the theoretical-methodological perspective of the Discourse Analysis of the French line. The theme that crosses the production is the question of being a woman from the experience of the transsexual and peripheral body in relation to the urban space, therefore, social, inhabited by this person. In the light of this contemporary emblem, we bring to the debate the relationship between gender, sexuality and urban space, based on Linn da Quebrada's intersemiotic discursive practice, in order to rethink the forms of gender identity construction, starting from the deconstruction of cisheteronormativities, these given as natural. We will make a presentation on the key theme, gender and urban space. Here we are interested in discussing the social role that architecture plays in our culture, after that, we will briefly reflect on the used concepts and, then, we will expose our analysis.
\end{abstract}

Keywords: intersemiotic discursive practice; discursive ethos; queer; urban space.

"Ficou insustentável fingir que nós não existimos".

Linn da Quebrada

\section{Um território de controles normativos}

O desenho urbano do século XX, fruto do Movimento Moderno ${ }^{3}$, prometia a reestruturação das cidades, deixando-as mais funcionais, limpas e eficientes, portanto, modernas, tanto pela promessa da ótima circulação de indivíduos - e carros - como também pelo ilusório fim de um déficit habitacional, que na realidade dobraria de tamanho com o passar das décadas. A sociedade, principalmente a europeia, devastada após duas guerras, necessitava de uma arquitetura rápida e funcional que devolvesse a vida para suas cidades, o que ficou a cargo dos arquitetos e urbanistas modernistas. Firmados pelos seus predecessores iluministas, que concebiam cidades como artérias e veias, os urbanistas modernos colocaram esse imaginário a serviço da população (Cf. SENNETT, 2016). A declaração dos $\mathrm{CIAM}^{4}$, de 1928, enfatizou a construção, e não a arquitetura, como

\footnotetext{
30 movimento moderno não se limitou apenas à arquitetura, mas envolveu aspectos ligados às áreas sociais, tecnológicas, econômicas e artísticas. No campo da arquitetura, os profissionais buscavam um estilo racional e funcional, para espaços públicos e privados, onde pudessem se desligar da história em busca do novo.

4 Congresso Internacional de Arquitetura Moderna. Realizado para decidir e planejar o futuro e a vida das/nas cidades. FRAMPTON, K. História crítica da arquitetura moderna. 2. ed. São Paulo: Martins Fontes, 2008.
} 
"a atividade elementar do homem, intimamente ligada à evolução e ao desenvolvimento da vida humana" (Cf. FRAMPTON, 2008). Ao fazê-lo, defendia a introdução de dimensões normativas e métodos de produção arquitetônica diretamente ligados à racionalização da cidade, consequentemente, dos hábitos e costumes.

Noventa anos depois, a cidade converteu-se em um enorme laboratório social (Cf. CORTÉS, 2008) onde, combinando a prática arquitetônica com a reflexão teórica, aprendeu-se que a configuração da cidade é um reflexo exato da realidade social em um determinado momento histórico e que as formas espaciais são consideradas estruturas criadas pela força humana que proclamam os interesses dos setores sociais dominantes (Cf. CORTÉS, 2008), a saber, os interesses masculinos.

Portanto, com a reflexão acerca das relações de poder dominantes no território e a crescente resistência por parte dos novos atores sociais da história, os espaços urbanos - públicos, principalmente - assumiram um caráter muito mais político, tanto no sentido do socialmente construído, como também em relação à forma de ocupação espacial. Hoje em dia, o sentido de ocupar é amplo e se expande em relação a um sujeito que não habita somente sua moradia física, mas reside em seus hábitos, costumes e vestimentas (Cf. REQUENA, 2007), ou seja, no seu corpo físico, expressando-se na sua maneira de ocupar a cidade. Consequentemente, estarão excluídos os sujeitos quando não incluídos nas categorias binárias de gênero e sexo, que o planejamento e o espaço urbano supõem.

O urbanismo do século XX, mais precisamente após a década de 50, foi uma estratégia de higienização urbana que resultou em uma higienização humana. De acordo com Segawa (2010), pretendia-se embelezar as cidades nos moldes da cidade europeia, tendo como referência o modo de viver dessa sociedade. Assim, a configuração territorial adotada, que é a que vemos hoje, foi realizada no modelo da Haussmanization ${ }^{5}$, que fragmentou e segregou os espaços urbanos, além de apoiar um controle militar da população (Cf. GEHL, 2015) e, por isso, é um exemplo da expressão espacial e social de uma dominação institucionalizada, masculina.

Recorremos a Pierre Bourdieu para mostrar que a dominação masculina funciona em conjuntura com as estruturas sociais relacionadas ao gênero e ao espaço, o que acontece tanto em âmbito público quanto privado. Como o sociólogo propõe, através da Família, a Igreja e a Escola:

5 Foi uma estratégica renovação urbana de Paris, realizada em 1852 pelo Barão Haussmann. Sua característica mais marcante foi a abertura de grandes bulevares, que aglomeravam pessoas ao mesmo tempo que era possível controlá-las. GEHL, J. Cidades para pessoas. Tradução Anita Di Marco. 3. ed. São Paulo: Perspectiva, 2015. 
[...] a ordem social funciona como uma imensa máquina simbólica que tende a ratificar a dominação masculina sobre a qual se alicerça: é a divisão social do trabalho, distribuição bastante estrita das atividades atribuídas a cada um dos dois sexos, de seu local, seu momento, seus instrumentos; é a estrutura do espaço, opondo o lugar de assembleia ou de mercado, reservado aos homens, e a casa, reservada às mulheres; ou, no interior desta, entre a parte masculina, como o salão, e a parte feminina, como o estábulo, a água e os vegetais; é a estrutura do tempo, a jornada, o ano agrário, ou o ciclo da vida como momentos de ruptura, masculinos, e longos períodos de gestação, femininos. (BOURDIEU, 1999, p. 18).

Portanto, a arquitetura - em todas as suas escalas - contribui para a configuração de estruturas sociais e ao mesmo tempo que confere autoridade a um modo de ser no mundo, o masculino, imprime sobre os outros corpos um forte controle social. Dessa forma, o homem viril apropria-se do entorno urbano, o controla e vigia (Cf. CORTÉS, 2008), fazendo assim parecer existir um único corpo, sexo e gênero, o masculino.

Podemos também pensar a relação entre corpo e espaço com Michel Foucault, que considera a arquitetura como a representação da autoridade e da ordem, além de ser a expressão de uma sociedade que age de modo disciplinar (Cf. CORTÉS, 2008). Ao conceito de pan-óptico do autor - uma máquina que tudo capta e tudo vê, portanto tudo controla - relacionamos a arquitetura, o espaço e suas instituições/estruturas sociais. Destacamos, aqui, dois exemplos em diferentes momentos da história, que nos mostram como o controle do território e do corpo sempre aconteceu.

O primeiro refere-se às instituições mais antigas: presídios, escolas, hospitais e, mais recentemente, os condomínios fechados que emergiram nas cidades a partir dos anos 1970. São espaços onde os aspectos formais de concepção arquitetônica (ou seja, o modo de concebê-los e realizá-los) têm características praticamente iguais, atribuindo sutilmente a diferentes espaços um mesmo uso, ou seja, uma arquitetura vigilante que indica um modo de se comportar, onde os seus usuários se autovigiam e a vigilância é um componente encontrado em todas as formas de organização relacionadas à modernidade (Cf. CORTÉS, 2008). As construções citadas acima foram concebidas em maior ou menor grau, a partir das ideias do familistério de Jean-Baptiste Godin, construído entre 1859-70, que buscava instaurar uma transformação territorial urbana (Cf. FRAMPTON, 2008).

O complexo, com 18 hectares de habitações destinadas aos operários, foi criado pelo arquiteto ao lado de uma fábrica e continha três blocos residenciais abastecidos com creche, jardim de infância, teatro, escola, banheiros públicos e lavanderia. Em formato retangular, cada bloco residencial tinha em seu centro um pátio com a iluminação vinda do alto; dos corredores que faziam as vezes das ruas, era possível visualizar todas as portas de entrada dos apartamentos; e o pátio tomava o lugar da praça pública. 0 conjunto pretendia, assim, ser uma cidade fechada a favor da vida familiar cooperativa. Pensando com Foucault (CORTÉS, 2008, p. 29), a proposta arquitetônica de Godin: 
[...] centra-se em uma arquitetura que olha, espia, controla e vigia, uma arquitetura voltada para o interior, que possui objetivos disciplinares e uma tecnologia de poder sutil que pretende uma transformação mais profunda do indivíduo; uma máquina de produzir sujeitos que se vigiam e se reprimem mutuamente.

Isto quer dizer, uma arquitetura voltada para os valores familiares e de trabalho, que se autovigia pelo comportamento, modos e costumes tidos como adequados. Embora essa arquitetura e as relações sociais que ela evoca estejam focadas no espaço doméstico, as fronteiras entre o público e o privado contidas nesse lugar são opacas, e ultrapassam o público e o privado, isto é, se fundem nas (rel)ações que o espaço possibilita. Não se trata apenas de controlar um modo de ser doméstico ou reduzido estritamente a uma esfera privada, mas é a extensão desse controle ao modo como os corpos utilizam outros espaços - os lugares de lazer, teatro, praça, rua... - os limites do controle são estendidos aqui a uma dimensão social muito mais complexa.

Outro exemplo de construção emblemática que representa o poder, controla e vigia, mas ao mesmo tempo mascara essa relação, é o arranha-céu, a torre contemporânea, fruto do século XX e ícone moderno do século XXI. Mascara porque foi convertido em um logotipo de progresso e modernização das cidades, porém, é o símbolo mais emblemático do ego masculino controlador projetado no espaço urbano (Cf. CORTÉS, 2008), com sua presença icônica, uma metáfora em relação ao poder do olhar e do controle social, com seu formato fálico, pretendendo demarcar uma posição de domínio.

Os edifícios são a mais evidente representação da globalização econômica, do poder e avanço tecnológico da construção das cidades modernas, portanto, é necessário analisá-los. Não nos cabe aqui dizer sobre o seu surgimento ou consequências, mas nos interessa o seu poder em nossa cultura. Louis Sullivan, arquiteto conhecido como o "pai dos arranha-céus", deixou no início do século XX a seguinte declaração sobre um edifício:

[...] vocês têm aqui um homem para observar, uma força viril, todo um símbolo da masculinidade. Ergue-se como um fato físico, como um monumento ao comércio, ao espírito dos negócios, ao poder e ao progresso da época, à resistência e à capacidade individual e à força de caráter. Por isso, em um mundo de mesquinhez estéril, fiz referência a ele como um homem porque evoca o poder criador, ao passo que outros cantaram a mestiçagem. (SULLIVAN, 1979, p. 204 apud CORTÉS, 2008, p. 144).

Portanto, aqui temos uma declaração de princípios, onde a existência dos edifícios diz respeito aos aspectos de caráter psicológico muito mais do que físico. O arranha-céu aparece como o apogeu da simbologia patriarcal, fundindo suas raízes em uma mística masculina na qual ressaltam, especialmente, o grande, o ereto e o forte (Cf. CORTÉS, 2008). Dessa forma, a relação entre o homem e seu edifício é hierárquica e acontece no 
eixo vertical, pois atribui-se ao estado ereto a condição primordial de sua existência, estar de pé. Nesse processo de identificação, em um edifício corporativo, por exemplo, é claro e natural que aquele que ocupa o maior cargo se instale no mais alto andar, o que the permite, além de tudo, vigiar as pessoas em posições inferiores (de novo o conceito de pan-óptico de Foucault). Trata-se de uma hierarquia clara que delimita também o espaço social: em cima está o poder tecnológico, político e econômico, e embaixo a multidão confusa (Cf. CORTÉS, 2008).

Porém, os espaços contêm diferentes significados que Ihes são atribuídos pelos diferentes usos e a arquitetura ajuda a construir esse imaginário de ser no mundo, mas não só isso - ela proporciona além do refúgio físico, o psicológico e tem sido uma guardiã de identidades (Cf. DE BOTTON, 2007). Logo, podemos - tanto arquitetos criadores de espaços, quanto usuários - propiciar a criação de espaços excludentes ou de convivência. Por exemplo, ao projetar uma casa, instância mais privada e íntima de nossas vidas, podemos sugerir que esse espaço se torne um lugar de acolhimento ou de reclusão. As ruas podem ser espaços de descoberta e libertação para os gays, ao ponto que para as mulheres podem se tornar lugares perigosos (Cf. CORTÉS, 2008). Portanto, a arquitetura e a cidade só existem e significam a partir da ação humana.

De acordo com esses e outros motivos deveríamos saber que não se vive no ambiente doméstico da mesma forma, muito menos no ambiente urbano. Cada cidadão traz consigo uma infinidade de características que condicionam suas vivências. São homens, mulheres, gays, lésbicas, trans, idosos, jovens, imigrantes e outros que configuram a cidade em que vivemos, através de suas "cidades particulares" e usos (Cf. CORTÉS, 2008), ou seja, essas cidades todas coexistem. Deste modo, a cidade, com sua disposição geográfica particular, planejada pelos arquitetos e urbanistas vinculados ao poder, se opõe à cidade praticada pelos indivíduos que a usam no dia a dia e que the conferem conteúdo com seus atos cotidianos (Cf. CORTÉS, 2008). Cada grupo social necessita encontrar espaços, lugares e signos com os quais se identifica.

Logo, o espaço urbano é um lugar onde as diferentes existências coexistem, assim como os diferentes poderes, mesmo com a arquitetura mais tradicional tentando inibir as diferenças sociais, sexuais ou de gênero. A cidade é o território onde os espaços são amplamente ocupados pelos setores majoritários, enquanto para as minorias essa cidade converteu-se em uma experiência de trânsito.

\section{Espaços em movimento: do tempo e do desejo}

Descrevemos acima o pan-óptico, conceito de Foucault que nos permite enxergar a partir de uma metáfora a ação do heterossexismo e o poder da dominação masculina na organização dos espaços, público ou privado. Considerando-o como uma máquina de visão total que tudo capta e tudo vê, portanto, tudo controla, a visão masculina, de 
acordo com Cortés (2008, p. 159), "tem uma função muito similar, pois funciona como um instrumento de coação ideológica com claros objetivos de controle" [sexual neste caso], ou seja, um olhar de supremacia que contém uma homofobia e misoginia internalizada. Essa situação urbana, reforçada por grandes espaços com grandes edifícios, cria muitas vezes um ambiente impessoal, formal e frio (Cf. GEHL, 2015). Atualmente, as grandes áreas urbanas são com frequência enormes agrupamentos de edifícios autossuficientes, espetaculares, isolados, entre estacionamentos e grandes vias, tudo muito gelado e frio assim como o concreto, o que inibe de diversas formas o surgimento da diversidade.

De acordo com Cortés (2008, p. 160), "cada lugar possui sua própria lógica de reprodução, seus próprios meios de perpetuação, bem como suas próprias condições de existência". Logo, os lugares são processos de reprodução social, por isso, impossível separar suas questões espaciais e culturais, já que para compreender um é necessário conhecer o outro. Portanto, usar um espaço é ter a capacidade de dotá-lo de conteúdo, contraditório ou diferente do que foi imposto primeiramente, pois é na medida em que é usado que um espaço existe (Cf. CORTÉS, 2008).

Dessa forma, uma das ações mais transgressoras no ambiente urbano tem sido o modo como diversas minorias ocupam e questionam o sentido de espaço ou a relação de seus corpos, seus desejos com a ideia de construção de um "lugar", de uma identidade, de uma cidade, de uma comunidade de corpos (Cf. CORTÉS, 2008).

Os gays foram os primeiros a recriarem seu próprio "mundo" na cidade ocidental, apoderando-se de lugares diversos para torná-los seus sem que a cidade majoritária tivesse total percepção disso (Cf. CORTÉS, 2008). Recriar o seu próprio mundo é, de acordo com Park (1967, p. 3), "a tentativa mais coerente e, em termos gerais, mais bemsucedida de refazer o mundo em que vive, e de fazê-lo de acordo com seus mais profundos desejos". Assim, ao fazê-lo, com sua presença e suas ações, tais grupos transformavam os espaços e lhes conferiam no mínimo um conteúdo diferente, quando não subversivo, do que até então havia existido ali, ressignificando o espaço público/privado e suas relações, seus corpos e desejos.

Dessa forma, redirecionaram o uso dos espaços públicos - ruas, praças, parques, praias, banheiros públicos, etc. -, ocupando esses espaços urbanos que lhes permitiam socializarse e assim, construir um mapa da cidade gay com diferentes pontos de encontro - sexuais ou não - que permanece desconhecido para a maioria dos cidadãos.

Em outra tomada, em contrapartida aos espaços frios e autossuficientes da cidade formal, outra grande aglomeração compõe o território da maioria das metrópoles, as favelas em constante transformação e crescimento. São os espaços em movimento, do tempo e do desejo de seus habitantes. O tecido urbano das favelas é flexível e maleável, o que determina o caminho a seguir é o próprio percurso, diferente da cidade formal 
planejada onde se pretende instalar a ordem. As favelas possuem uma identidade espacial própria e são diferentes entre si. O que causa a diferença é a temporalidade (Cf. VARELLA; BERTAZZO; JACQUES, 2002), em diferentes níveis.

Inicialmente, a temporalidade das favelas é diferente da cidade formal em termos de construção. Enquanto na cidade tudo é planejado e tem um projeto que determina o seu fim, nas favelas, os barracos são construídos a partir de fragmentos encontrados ao acaso (Cf. VARELLA; BERTAZZO; JACQUES, 2002), são nômades em questões formais. Esse abrigo será adaptável e crescerá de forma única e de acordo com as necessidades e desejos do seu morador que, na maioria das vezes, é também o construtor junto com amigos e vizinhos (princípio de mutirão), o que atribui um sentimento de identificação único com o lugar.

Nas favelas, o sentido de público e privado é o oposto ao familistério de Godin. Ao longo do dia, as ruelas se tornam a extensão das casas, como espaços semiprivados, e as casas, por sua vez, com as portas abertas, se transformam em espaços semipúblicos (Cf. VARELLA; BERTAZZO; JACQUES, 2002). Assim, o espaço urbano das favelas propõe uma proximidade física diferente, como se a mesma fosse uma grande casa coletiva, diferente do ambiente de Godin, que propõe uma cidade cercada por muros.

Outro fator que diferencia as cidades formais das favelas, portanto, diz respeito também ao modo como esses sujeitos ocupam o espaço urbano: é o movimento, uma experiência de trânsito. As favelas são espaços em movimento e esse espaço é diretamente ligado aos seus atores (sujeitos de ação) (Cf. VARELLA; BERTAZZO; JACQUES, 2002).

É nesse sentido - de transgressão do espaço e do corpo - que nos interessa discutir sobre a prática discursiva intersemiótica de Linn da Quebrada e a construção de um ethos discursivo a partir de um não-lugar6 (Cf. AUGÉ, 1998). Corpos que fogem a padrões naturalizados de gênero e sexualidade vivenciam uma experiência de trânsito, entre centro e periferia, entre lugares e não-lugares, ou seja, na maior parte das vezes, ocupam espaços do anonimato e da impossibilidade de construção de afetos duradouros ou, em outros momentos, aparecem avançando nos espaços majoritários por sua arte, ativismo

\footnotetext{
6 Augé relaciona o conceito de "não-lugar" aos lugares pelos quais não se estabelece uma conexão afetuosa, ou seja, o autor nos diz sobre espaços frequentemente ocupados, por exemplo, infraestruturas completas, rodovias que contam com hotéis, shoppings etc. ou até mesmo aeroportos, onde é possível instalar-se sem nenhum problema. Aqui utilizamos o conceito do autor, principalmente pelo fato do não-lugar não permitir uma construção de afeto, para relacionálo com os lugares esquecidos na cidade - lixões, esgotos, garagens, favelas, etc. - que tais corpos ocupam, vivenciando então uma experiência de trânsito. CORTÉS, J. M. G. Políticas do espaço: arquitetura, gênero e controle social. Tradução Silvana Cobucci Leite. São Paulo: Editora Senac São Paulo, 2008.
} 
etc., como uma resposta em relação ao conservadorismo. São esses indivíduos e grupos que vivenciam os efeitos de uma política sexual de forma mais intensa e até mortal (Cf. SPARGO, 2017). Permitem assim, com suas vidas e corpos, novas formas de questionar as identidades humanas, ao desafiarem as concepções binárias tradicionalmente construídas, por exemplo, heterossexual e homossexual, homem e mulher, público e privado etc..

Deste modo, para essa parcela da população, o centro das cidades torna-se um espaço de passagem, onde podem experimentar alguns aspectos de sua sexualidade e variadas performances de gênero, mas não lhes é dado viver plenamente ali. Também as periferias não os aceitam como são, da mesma forma que enfrentam uma certa resistência nos espaços que já estão estabelecidos pelos gays, onde também existe a predominância de um olhar e um poder masculino.

Nesse contexto, Linn da Quebrada assume um lugar de sujeito em processo, um corpo que reivindica a sua existência e de outras pessoas como ela, através de uma prática discursiva hiperbólica, que utiliza elementos até então tidos como indícios de fragilidade, para construir um corpo que transgride as cisheteronormas, corporais e espaciais.

\section{Prática discursiva, ethos e cenografia}

Dominique Maingueneau, em Gênese dos Discursos, sugere que a prática discursiva pode ser considerada uma prática intersemiótica, pois diz respeito não somente à integração de um conjunto de enunciados, mas também de produções que abordam diferentes domínios semióticos como o musical, o pictórico, o literário, dentre outros (Cf. MUSSALIM, 2001). Não há nenhuma razão forte o bastante para não considerar materialidades, como filmes, pinturas, músicas, videoclipes etc., como "textos". A concepção de uma semântica global do discurso, integrando todos os planos discursivos ao mesmo tempo (Cf. MAINGUENEAU, 2008), se apresenta então como método de análise, em que o importante para o analista do discurso é a significância discursiva e não uma hierarquia dos elementos:

[...] o discurso não é nem um sistema de "ideias", nem uma totalidade estratificada que poderíamos decompor mecanicamente, nem uma dispersão de ruínas passível de levantamentos topográficos, mas um sistema de regras que define a especificidade de uma enunciação. (MAINGUENEAU, 2008, p. 19).

Portanto, Maingueneau (2008) indica que não se deve restringir apenas ao domínio textual a validade do sistema de restrições semânticas de um discurso, pois tal sistema recai sobre outros tipos de estruturas semióticas. Dessa forma, falar sobre um mesmo sistema semântico para diversas práticas intersemióticas supõe compreender o conceito de "competência discursiva" como uma rede de regras à disposição dos enunciadores 
(Cf. MUSSALIM, 2001). Assim, o pintor, o arquiteto, dado que participam da mesma prática discursiva, dispõem da mesma rede de regras que os enunciadores para tratar os materiais significantes (Cf. MAINGUENEAU, 2005, p. 148).

Já a noção de ethos é primeiramente apresentada por Aristóteles em sua Arte Retórica como a persuasão baseada na imagem que o orador oferece de si ao ouvinte, independentemente de qualquer opinião prévia que se tenha. Maingueneau, ao incorporar o ethos retórico ao campo da Análise do Discurso (AD), reinterpreta essa noção, propondo que o que o enunciador deseja causar sobre seu auditório por meio da sua imagem é imposto pela formação discursiva e não pelo sujeito em si (Cf. PIRIS, 2007). Portanto, o ethos diz respeito a uma noção discursiva, ele se constrói pelo discurso e no discurso e mesmo quando escrito, é sustentado por uma voz, de um sujeito situado além do texto (Cf. MAINGUENEAU, 2013). Para Maingueneau (2013), esse "tom" dá autoridade ao que é dito e associa-se a um caráter e a uma corporalidade, que compreendem não só a dimensão vocal, mas também a física e psíquica, ligadas à representação coletiva da personagem do enunciador, ou seja, uma voz e um corpo historicamente investidos de valores compartilhados socialmente e captados por meio de estereótipos.

Desse modo, o ethos deve ainda ser compatível com o mundo que é construído no discurso por meio de uma cenografia. De acordo com Maingueneau (2013), a cenografia é a cena com que o co-enunciador toma contato explicitamente, ela tende a deslocar o quadro cênico (cena englobante e cena genérica) para o segundo plano. Para nossa análise, mobilizaremos os conceitos de ethos discursivo, cenografia e código linguageiro, tomados como motores da paratopia criadora da artista (Cf. MAINGUENEAU, 2006).

\section{0 corpo (trans)crito no discurso}

Trazemos para análise a música "Mulher", que faz parte da obra audiovisual blasFêmea, da artista Linn da Quebrada. O tema que atravessa a produção é a questão do ser mulher, contada a partir da experiência urbana do corpo transexual, preto e periférico, e de suas relações com os espaços que the são impostos compulsoriamente. O videoclipe em questão envolve três momentos narrativos: um prólogo, onde se expõe a desconstrução do culto ao falocentrismo, uma narrativa central - que é o momento onde a música é apresentada, o foco dessa análise - onde as mulheres e seus corpos são significadas através da periferia da cidade de São Paulo, e um epílogo, que exibe cenas de uma vivência real com todas as mulheres que participaram da gravação do vídeo. Abaixo apresentamos as sequências discursivas que formam a letra da canção.

A propósito da cena de enunciação desse texto, pode-se dizer, de acordo com as considerações de Maingueneau, que sua cena englobante é o discurso litero-musical e sua cena genérica é a letra de canção. Essas são as duas dimensões que constituem o quadro cênico do texto. No entanto, não é em relação a esse quadro que o co-enunciador 
se vê confrontado, mas sim a uma cenografia que distingue esse "texto" de outras letras de canções. Tal cenografia não foi escolhida ao acaso, mas como a mais adequada para dizer o que se pretende dizer. Embora o texto seja construído com versos que pareçam com qualquer letra de canção, o leitor está diante de um manifesto (cenografia), utilizado de maneira poética, unindo o protesto com uma ação artística, ação frequente na prática discursiva intersemiótica da artista. A canção se diferencia pelo fato de não ter um refrão e não apresentar um sistema intercalado entre versos e refrão, uma característica "anticomercial" também presente na prática discursiva da artista, que se opõe aos interesses, normas e usos comerciais. No manifesto, um grupo ou pessoa se posiciona frente a determinadas problemáticas que podem ser sociais, culturais, políticas ou religiosas.

O título da canção (Mulher) antecede o que será tratado no corpo do texto, que expõe os motivos pelos quais elas, mulheres, são a pauta da discussão. Dessa forma, a canção organiza e dispõe informações sobre determinado grupo e também sobre determinado modo de vida nas periferias da cidade de São Paulo. Os versos são construídos como enunciados definitórios que reinterpretam as categorias binárias de identidade de gênero e sexo dadas como naturais, relacionando-as com os espaços ocupados por esses corpos - "não é homem, nem mulher, é uma trava feminina, é diva da sarjeta, seu corpo é uma ocupação, é favela...".

A essa cenografia associa-se um ethos de agressividade, que denuncia a situação dos corpos jogados às margens das cidades. Desse modo, a força desse ethos se deve ao fato de que ele envolve um tom que dá autoridade ao que é dito. Esse tom permite ao leitor construir uma representação do corpo do enunciador (o que está inscrito no discurso) (Cf. MAINGUENEAU, 2013). Portanto, a harmonia entre essa voz e o conteúdo que enuncia é fundamental para conferir ao texto um efeito de verossimilhança, necessário para interpelar o "leitor", não só como um mero ouvinte da música, mas também com alguém que se sinta incomodado e/ou representado pelo que está sendo dito. Desse modo, a cenografia possibilita a gestão dos sentidos que o discurso constrói para as experiências e vivências de gênero e sexo na cidade da perspectiva de um corpo transexual. A partir da cenografia, do ethos, do tom, entre outros elementos citados acima, o coenunciador "constrói" um "corpo" que está imbricado com a enunciação, conferindo sentido ao que é dito.

\section{Sequência Discursiva 7:}

De noite pelas calçadas/Andando de esquina em esquina/Não é homem nem mulher/É uma trava feminina/Parou entre uns edifícios/mostrou todos os seus orifícios/Ela é diva da sarjeta/o seu corpo é uma ocupação/ É favela, garagem, esgoto e/pro seu desgosto/tá sempre em desconstrução//Nas ruas pelas surdinas é onde faz o seu salário/Aluga o corpo a pobre, rico, endividado, milionário/Não tem Deus/Nem pátria amada/Nem marido, nem patrão//O medo aqui não faz parte do seu vil vocabulário/Ela é tão singular//só se contenta com plurais/ Ela não quer pau/ela quer paz/ 
A letra da canção associa os corpos aos espaços e às condições de vida e trabalho compulsoriamente dados aos corpos abjetos (Cf. BUTLER, 2001, 2017). Por sua própria enunciação, o texto incorpora as propriedades associadas ao comportamento de travestis que trabalham com a prostituição - "divas da sarjeta" -, subvertendo-lhe o sentido pejorativo e ecoando como palavras de ordem em um discurso de imposição de um feminino que se manifesta independentemente da genitália, descontruindo o ideal cisheteronormativo de mulher: "não é homem nem mulher, é uma trava feminina" e "o seu corpo [...] está sempre em desconstrução". Não definindo o corpo como uma unidade de nenhum dos sexos, esse enunciado retoma elementos da memória discursiva, que atribui aos travestis e transexuais ora dois sexos, ora sexo algum, no sentido de incompletude, de impossibilidade de ser pleno.

O corpo feminino construído pela enunciação como fora da cisheteronormas associase aos "não lugares" (Cf. AUGÉ, 1998), em modo de analogia: "sarjeta, ocupação, favela, garagem, esgoto". São os espaços do anonimato - onde é permitida sua existência, pois ali não existe vida social regulada e investida de valores positivos, de afeto. Esses espaços urbanos, habitados por diferentes corporalidades, condicionam as formas de vida e as práticas sociais cotidianas. Todo elemento construído ajuda a estabilizar uma ordem e uma identidade espacial (Cf. CORTÉS, 2008). Portanto, aos corpos que fogem das normas e padrões sociais que incluem também as normas de gênero e sexo, a possibilidade de existência é a partir de um não-lugar ou da reinvenção de um lugar, por exemplo, o centro das cidades, onde esse corpo feminino construído pelo discurso está revolucionando os valores da cidade majoritária parando entre os edifícios - locais de moradia, trabalho e de grandes empresas corporativas - e mostrando todos os seus orifícios, ou seja, inventando a sua existência no espaço urbano tradicional, atribuindo-Ihe um conteúdo diferente do que existiu ali até então.

O enunciado "nas ruas, pela surdina, é onde faz o seu salário" ironiza os lugares de trabalhos formais, os grandes edifícios de escritórios etc., já que elas trabalham no escuro, único lugar onde seus corpos são desejados. A prática discursiva de Linn nos indica também a relação entre esses corpos, espaços e classes sociais: "aluga o corpo a pobre, rico, endividado, milionário": aluga, não vende, pois o uso é temporário, pode ser por qualquer um que pague, mas o corpo permanece dela.

"Não tem Deus, nem pátria amada, nem marido, nem patrão", enunciado que constrói um efeito de sentido de que esses corpos não são dignos de habitar as cidades, um espaço social, não são corpos cidadãos. Tais pessoas não podem ter Deus, porque a religião as renega; não têm pátria, porque a sociedade em que vivem não as aceitam como são; não têm marido, porque não são dignas de relacionamentos afetivos; e nem patrão têm, porque o mercado de trabalho para elas não existe. Estão destinadas à prostituição, ou seja, todo o espaço social é renegado a um corpo que performa o feminino sem que haja coincidência entre esse feminino e o sexo biológico. Esse enunciado nos permite ainda 
entender, não pelo que está dito, mas pelo que é negado, como os cidadãos - homens brancos, heterossexuais - construíram suas redes de apoio e de estímulo, financeiro, emocional e psicológico, onde esse feminino está ou subordinado - pelo casamento - ou totalmente excluído - pelas práticas sexuais desviantes. No entorno urbano, o corpo das mulheres e dos gays - entre outras minorias - estiveram ausentes ou foram silenciados por hierarquias e prioridades que favorecem determinados valores e anulam outros. Desse modo, o homem viril se apropria, controla e vigia o entorno urbano e simboliza, distribui e utiliza do mesmo (Cf. CORTÉS, 2008) de acordo com seus interesses. Assim, a esses corpos resta uma sobrevivência segmentada. Enquanto a sociedade majoritária dorme, a cidade queer vive, criando sua própria "cidade" dentro da cidade genérica, ocupando lugares em determinadas horas para dotá-los de "novos" significados. (Cf. CORTÉS, 2008). Os diferentes espaços se transformam com a presença desses corpos e seus atos, que atribuem um conteúdo no mínimo diferente do que tais espaços até então haviam tido.

O ethos discursivo (Cf. MAINGUENEAU, 2006) que emerge reúne traços de ironia e agressividade. A palavra vem acompanhada da sonoridade, que é áspera, provocante, um som urbano e acessível - o ritmo é o funk - e não apenas diz o que diz, mas mostra o que diz, profetizando no próprio texto essa mulher, dona de si, de suas vontades e do seu corpo, que cria seus próprios roteiros, suas múltiplas existências, provocando o coenunciador, o macho opressor, desconstruindo a masculinidade, por meio do jogo de palavras: "ela não quer pau, ela quer paz".

SD.2:

Seu segredo/ignorado por todos/e até pelo espelho//mulher...//Nem sempre há um homem para uma mulher/mas há dez mulheres para cada uma/e uma e mais uma e mais uma e mais uma/e outra mulher/e outra mulher/

O enunciado traz uma afırmação sobre o seu segredo: "ser mulher". Sujeito que acredita naquilo que é dito pelos outros sobre si mesma, mas, ao mesmo tempo, está tentando entender o que é ser mulher nesse corpo, tido como masculino demais, ou seja, ocupando um espaço de tensão entre o feminino e o masculino. Na canção, a palavra "mulher" é dita lentamente e ecoa como um pensamento. Ao mesmo tempo, o videoclipe mostra frames de diferentes mulheres pela periferia de São Paulo, cidade vista como o "sonho americano" das travestis, que enxergam na capital mais possibilidades para sua existência.

Na sequência, o enunciado traz a repetição do artigo feminino - uma - acompanhado da partícula "mais" e toda a sequência dessa repetição, antecedida e sucedida pelo substantivo mulher, cria um efeito de encadeamento: mulheres podem se apoiar umas nas outras. 
Mulher fala ainda dos afetos, dos sonhos e dos desejos de corpos femininos, para além das normatividades de gênero e de sexualidade, ou seja, desconstruindo a cisheteronormatividade. Desse modo, constrói um ethos de mulher com a qual outras mulheres - ou qualquer um - podem se identificar, e com essa identificação elas experimentam a sororidade (solidariedade entre mulheres).

\section{SD. 3:}

Ela tem cara de mulher/Ela tem corpo de mulher/Ela tem jeito/Tem bunda/Tem peito/E o pau de mulher!/

Observa-se, com esse enunciado, a força dominante nas interpretações sobre sexo e gênero, já socialmente construídas: "ela tem corpo e cara de mulher". É um exemplo onde é possível ver as dinâmicas de construção discursiva de gênero e sexo como separadas, porém conectadas (Cf. SPARGO, 2017). A esse imaginário social sobre ser homem/ mulher, o discurso combina signos convencionais de gêneros opostos - peito e pau -, construindo o sentido de que ela não se enquadra claramente nas categorias binárias, masculino=homem e feminino=mulher. Sua performance perturba o saber convencional a respeito da aparência que o gênero masculino/feminino deve ter, afınal, o enunciado diz "mulher de pau".

Essa expressão é vista por muitos como uma nova linguagem da travestilidade, com corpos que não utilizam de próteses para se submeter ao imaginário coletivo do "ser mulher" e, ao mesmo tempo, confronta toda a sabedoria que ronda a masculinidade, pois essa "mulher de pau" é aquela que vai à luta pelos seus direitos e desejos. Ou seja, assim como a linguagem, o corpo também é vivo, e na época em que vivemos já está insustentável negar novas existências. Assim, não há uma relação necessária entre o corpo de alguém e seu gênero, sendo possível que um corpo identificado como fêmea não exiba traços femininos. Em outras palavras, é possível ser uma fêmea masculina ou um macho feminino (Cf. BUTLER, 1990 apud SALIH, 2017). Através dessa construção discursiva sobre um gênero específico - o feminino - podemos entender que a prática discursiva de Linn da Quebrada é política; uma prática discursiva que se apresenta como um discurso feminista trans, mas que não quer política de identidades fixas. Sua prática discursiva propõe identidades sem essências e sujeitos sempre em processo.

SD. 4:

Afinal//Ela é feita pra sangrar/Pra entrar é só cuspir/E se pagar/Ela dá/Para qualquer um/Mas, só se pagar ein!/Que ela dá, viu, para qualquer um/

O advérbio "afinal" indica uma afirmação ao modo de ser e a um lugar que esses corpos abjetos ocupam, em concordância com o que foi compulsoriamente dito e imposto sobre sua própria existência, retomando o sentido construído com o enunciado na primeira parte da canção (SD.1). 
Afınal, para tais corpos só resta a prostituição, onde são expostas a todos os tipos de práticas sexuais e fetiches ao qual seu corpo está associado, pois "ela é feita pra sangrar, pra entrar é só cuspir, e se pagar, ela dá, para qualquer um". No final, essa mulher "imperfeita" continua sozinha, já que seu corpo não pode lhe conferir status de gente, passa do fetiche para a solidão, que também é compulsória.

\section{SD. 5:}

Então, eu/Bato palmas para as travestis que lutam para existir/E a cada dia conquistar/O seu direito de viver e brilhar/Viver, brilhar e arrasar//Ela é amapô de carne, osso, silicone industrial/ Navalha na boca/Calcinha de fio dental [...]/Navalha, navalha, valhal/Eu tô correndo de homem/ Eu tô correndo de homem//Homem que consome/Só come e some/Homem que consome/Só come, fudeu e some/Some/

Nos versos finais da letra de "Mulher", o enunciado reafirma a posição dessas mulheres no espaço social, aplaudindo as travestis que lutam pelos seus direitos de existir, viver, brilhar e arrasar, celebrando a vida dessas mulheres e colocando-as em oposição à violência que sofrem e não mais em uma posição submissa, mas sim de revolucionárias, que decidem pelo seu próprio corpo, por suas próprias relações.

Há, também, versos que apresentam um modo de ser no mundo (ou seja, temos uma compatibilidade entre um estereótipo social e o corpo social construído pela enunciação), com códigos de linguagem e expressões próprias (ou recorrentes) do mundo das travestis, das ruas, ou seja, é uma outra língua, que diz sobre outros corpos e lugares e não a língua majoritária das cidades. Portanto, o uso da língua que a obra implica - o Pajubá - se apresenta como a maneira pela qual se tem de enunciar, por ser esta a única maneira compatível com o universo que ela instaura (Cf. MAINGUENEAU, 2009). O verso em questão diz "ela é amapô de carne, osso, silicone industrial". "Amapô" vem do pajubá e significa mulher; a expressão "silicone industrial" remete ao mundo das travestis (mais uma vez) que frequentemente utilizam da substância para moldar o corpo de modo que se assemelhem ao ideal feminino de mulher. "Pajubá" é também o nome do disco de Linn da Quebrada que contém essa canção e é um dialeto que tem origem em línguas de matrizes africanas, utilizado como código pelas travestis e posteriormente adotado como gíria por toda comunidade LGBTQ+. O pajubá é falado em todo o Brasil e é uma língua móvel, assim como a população que a fala, por isso possui diferenças regionais. Tal código corrobora o ethos discursivo na enunciação, o que leva a um efeito de sentido de aderência entre um modo de comunicação considerado como participante do mundo que o próprio texto está evocando.

Na sequência, o enunciado "navalha na boca, calcinha de fio dental" recupera uma memória discursiva que faz parte do mundo LGBTQ+ e também fala dos estereótipos construídos socialmente de que as travestis são mulheres promíscuas e perigosas, que mostram o corpo - construído pelo silicone - e que andam armadas, para se proteger nas ruas. 
O universo de sentido propiciado pelo discurso impõe-se tanto pelo ethos como pelas ideias que se apresentam pelo intermédio de uma maneira de dizer que remete a uma maneira de ser (Cf. MAINGUENEAU, 2013).

Por fim, a canção traz um verso em rima, com as palavras homem, come e some. O enunciado constrói um efeito de sentido sobre o corpo feminino em forma de manifesto, conclamando os corpos a formarem redes de apoio entre si e que não sejam mais suscetíveis aos desejos e fetiches dos homens, além de sugerir novas formas de se relacionar para além das categorias binárias de identidade de gênero e também de sexo.

\section{Considerações finais}

Tomando como fundamento as reflexões de Maingueneau (2013), discutiu-se neste artigo o conceito de cenografia atrelado ao ethos discursivo. Na análise apresentada, observou-se que a cenografia construída pela letra da canção permite explicar questões importantes ligadas aos efeitos de sentido que o enunciado produz, além da relevância da cenografia na construção do ethos que capta papéis sociais culturalmente reconhecidos para atribui-los aos enunciadores, constituindo a dimensão criativa da produção discursiva, sem alterar o estatuto definido pelo quadro cênico. Algumas características da enunciação nos permitem afırmar a construção de um ethos combativo no discurso de Linn da Quebrada se adequando a sua respectiva cenografia.

A prática discursiva intersemiótica de Linn da Quebrada nos traz o questionamento, a partir do empoderamento feminino, sobre o que é ser mulher, o que é entendido como feminino, e porque corpos que carregam o feminino são considerados tão vulneráveis. A partir desses posicionamentos, essas mulheres e esse feminino vão sendo significados e significando a partir de suas vivências no espaço urbano, a saber, a cidade de São Paulo, se aproximando, assim, das jovens da periferia através do funk, ou seja, a partir da junção de dois lugares considerados "sem valor" - o funk e a favela - esse discurso se aproxima dos espaços aos quais ele está associado, que permitem o seu surgimento.

Sendo assim, a cenografia, o código linguageiro, são alguns dos conceitos que constituem a dimensão criativa da prática discursiva transgressora da artista, além de um ethos agressivo/combativo constituído a partir desse não-lugar, da vulnerabilidade. Dessa forma, o corpo negro, feminino, trans vai sendo significado a partir de sua vivência no espaço urbano da mesma forma que o espaço é significado por esses corpos. Portanto, as palavras possuem propriedades representativas das quais se servem para criar uma atmosfera indiciária do imaginário social no texto (Cf. FEDATTO, 2013), ou seja, sua evocação é capaz de fazê-lo aparecer para o leitor/ouvinte. Desse modo, a prática discursiva de Linn da Quebrada não é somente uma forma de expressão, ela é a matéria de significações possíveis para diversas realidades históricas que estão sendo construídas para além de todos os binarismos possíveis. 


\section{REFERÊNCIAS}

AUGÉ, M. Los no-lugares: espacios del anonimato. Barcelona: Gedisa, 1998.

BOURDIEU, P. A dominação masculina. Rio de Janeiro: Bertrand Brasil, 1999.

BUTLER, J. Problemas de gênero. Feminismo e subversão da identidade. 14. ed. Rio de Janeiro: Civilização brasileira, 2017.

BUTLER, J. Corpos que pensam: sobre os limites discursivos do "sexo". In: LOURO, G.

L. (org.). O corpo educado. Pedagogias da sexualidade. Belo Horizonte: Autêntica, 2001.

p. 153-172.

CORTÉS, J. M. G. Políticas do espaço: arquitetura, gênero e controle social. Tradução Silvana Cobucci Leite. São Paulo: Editora Senac São Paulo, 2008.

DE BOTTON, A. A arquitetura da felicidade. Tradução Talita M. Rodrigues. Rio de Janeiro: Rocco, 2007.

FEDATTO, C. P. Um saber das ruas. O discurso histórico sobre a cidade brasileira. Campinas: Editora da UNICAMP, 2013.

FRAMPTON, K. História crítica da arquitetura moderna. 2. ed. São Paulo: Martins Fontes, 2008.

GEHL, J. Cidades para pessoas. Tradução Anita Di Marco. 3. ed. São Paulo: Perspectiva, 2015.

MAINGUENEAU, D. Análise de textos de comunicação. São Paulo: Cortez. 2013.

MAINGUENEAU, D. Gênese dos discursos. São Paulo: Parábola, 2008.

MAINGUENEAU, D. Discurso Literário. São Paulo: Contexto, 2006.

MAINGUENEAU, D. Gênese dos discursos. Curitiba: Criar Edições, 2005.

MUSSALIM, F. Semântica Global: uma prática intersemiótica. 2001. 
PARK, R. On social control and coletive behaviour. Chicago. University Press, 1967, p. 3. In: HARVEY, D. Cidades Rebeldes: do direito a cidade à revolução urbana. São Paulo: Martins Fontes, 2014.

PIRIS, E. L. O papel da cenografia na construção do ethos discursivo: estudo de três pronunciamentos parlamentares que antecederam o Al-5. Estudos Linguísticos, São Paulo, v. XXXVI, n. 3, p. 182-190, set./dez. 2007.

REQUENA, C. A. J. Habitar híbrido: interatividade e experiência na era da cibercultura. Escola de Engenharia de São Carlos da Universidade de São Paulo, 2007.

SALIH. S. Judith Butler e a teoria queer. Belo Horizonte: Autêntica, 2017.

SEGAWA, H. Arquiteturas do Brasil 1900-1990. 3. ed. São Paulo: Editora da Universidade de São Paulo, 2010.

SENNETT, R. Carne e Pedra: o corpo e a cidade na civilização ocidental. Tradução Marcos Aarão Reis. 4. ed. Rio de Janeiro: Best Bolso, 2016.

SPARGO. T. Foucault e a teoria queer. Belo Horizonte: Autêntica, 2017.

VARELLA, D.; BERTAZZO, I.; JACQUES, P. B. Maré, vida na favela. Rio de Janeiro: Casa da Palavra, 2002. 